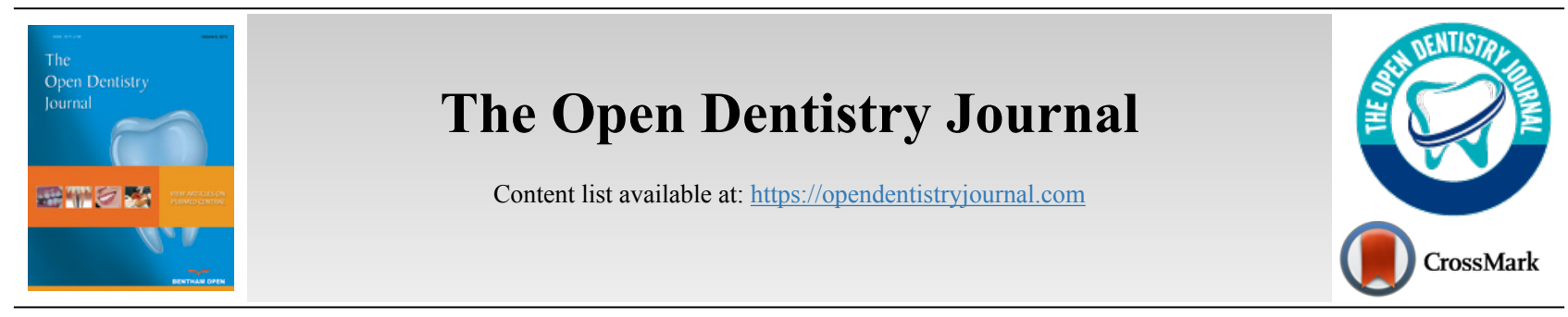

RESEARCH ARTICLE

\title{
Effect of Canine Dimensions on Smile Aesthetics among General Dentists, Dental Students and Laypersons
}

\author{
Amjad Al Taki ${ }^{1, *(D)}$ and Eyas Abuhijleh ${ }^{2}$ \\ ${ }^{I}$ Private Practice, Department of Orthodontics, Smile Spa Dental Clinic, Dubai, UAE \\ ${ }^{2}$ Department of Orthodontics, University of Science and Technology of Fujiarah, UAE
}

\begin{abstract}
:
Objectives:

Canines and their dimensions play a major role in the appearance of the smile. The aim of the study was to determine the perception of smile aesthetics among General dentists, Dental students, and laypersons, with respect to different levels of maxillary canine (canine tip height and gingival height in reference with central incisors) and Golden Proportions in regards to lateral incisor.

\section{Materials and Methods:}

This was a cross-sectional study conducted amongst three different populations; students of dentistry, general dentists and laypersons. A convenient sample size of 109 participants was accepted for the present study, out of which there were 41 students of dentistry, 38 general dentists and 30 laypersons. We used digitally altered photographs $(\mathrm{n}=15)$ for data collection.

\section{Statistical analysis:}

Kruskal Wallis Test was applied as a test of significance and the level of significance was set at $<0.05$

Results:

The most of the dental students found the canine tip (-0.5), the gingival height of $(+0.5)$ and the Golden Proportion $62 \%$ attractive. The majority of general dentists found the canine tip (-0.5), the gingival height of $(+1)$ and the Golden Proportion $72 \%$ attractive. In comparison, laypersons found the canine tip $(+0.5)$, the gingival height of $(0)$ and the Golden Proportion $57 \%$ attractive.

\section{Conclusion:}

The study demonstrated that the perceptions of dental students, general dentists and laypersons had a significant difference.

Keywords: Aesthetics, Canine Tooth, Perception, Smiling, Gingival height, Golden proportion.

\section{INTRODUCTION}

Visual impression while interpersonal communication plays a major role in human society and the smile is an important part of this impression. Although the perception of the smile is a highly subjective matter, over the years, a number of efforts are made to quantify this perception. The quantification of smile aesthetics has lead dentistry to a whole new level. The smile not only affects the social and interpersonal interactions, but also affects the self-confidence

\footnotetext{
* Address correspondence to this author at the Private Practice, Department of Orthodontics, Smile Spa Dental Clinic, Dubai, UAE;

E-mail: al taki@hotmail.com
}

\begin{tabular}{l|l} 
Revised: April 25, 2020 & Accepted: April 29, 2020
\end{tabular}

of a person [1]. A lot of studies have shown that the aesthetics of smile affect various aspects of social life, which include finding a relationship partner, personality development, performance at workplace and kinship opportunity [2]. Canines and their dimensions play a major role in the appearance of the smile. Apart from that, the relationship of canine width with lateral incisors, which is known as "Golden Proportion", also has a great impact on the perception of the observer. A smile 'designed' perfectly and according to the textbook, by the orthodontist, may not be the ideal smile for a layperson. Therefore, it is critical to identify the perspective of the client before offering him any services for smile aesthetics.
\end{abstract}


With advances in dentistry, it has been possible to 'design' the smile of an individual. However, in many instances, the perception of an ideal smile varies in people with different demographic backgrounds [3]. However, by understanding the perception of a patient, an orthodontist can optimise the shape of the teeth and height of gingival contours to provide the 'best smile' [4]. While smiling, central and lateral incisors are most visible and, therefore, have the maximum effect on the appearance. However, it has to be remembered that the mesial part of maxillary canines is also visible and can have an important effect on the smile aesthetics. The majority of the researches about smile aesthetics are based on the dimensions of central and lateral incisors. There exists a relative vacuum in terms of research on the role of maxillary canines on smile aesthetics. Changing gingival height can also influence the appearance of the smile, but the gingival margin of canines has little influence on it. But again, not many studies are done to evaluate this hypothesis. Therefore, the current study is based on the effect of dimensions of maxillary canines and gingival height on smile aesthetics. The study aims to determine the perception of smile aesthetics among general dentists, dental students, and laypersons, with respect to different levels of maxillary canine (canine tip height and gingival height in reference with central incisors) and Golden Proportions in regards to lateral incisor.

\section{MATERIALS AND METHODS}

The current study was a cross-sectional study conducted amongst three different populations; students of dentistry, general dentists and laypersons. A convenient sample size (in line with other similar studies) of 109 participants was accepted for the present study, out of which there were 41 students of dentistry, 38 general dentists (with no specialization) and 30 laypersons (college educated). Written informed consent was obtained from all participants.

\subsection{Data Collection Tools}

A photograph of smiling female patient was utilized to know the perceptions of study groups (students of dentistry, general dentists and laypersons) about the smile aesthetics. Multiple photographs were taken of a smiling female patient with a Nikon D750 DSLR camera. It is a camera with 24.3 megapixel resolution, CMOS image sensor, EXPEED image processor, $10 \mathrm{~mm}$ macro lens (Tokina Co.) and Sigma Flash ring EM 140-DG. An Sb-r200 twin flash system (Nikon Corp. Japan) was attached using an adjustable scorpion medical bracket (Agno's Tech Engineering Co.). To assure the high quality of photograph, the camera was set up with the following options: ISO $100,100 \mathrm{~mm}, \mathrm{f} / 45$, and $1 / 60 \mathrm{~s}$ exposure time. The photograph was taken at the same height as that of the subject and from a distance of 0.5 meters.

From 10 photographs, one photograph was selected based on the quality and study criteria by the investigators. It was ensured that the photograph was closest to the natural appearance, right positioned and taken in a good light. From this photograph, the only portion containing lips, gingiva and teeth was kept and other features of the face were removed. This photograph was modified using Adobe Photoshop CS6 photo-editing software (Adobe Systems Inc., San Jose, CA,
USA). The length and gingival height of canines in relation to central incisors and width of canines (to follow the rules of Golden Proportions) were altered in relation to the lateral incisors. Based on modifications, three sets of photographs were prepared and these digitally altered photographs were used for data collection Figs. (1-3).

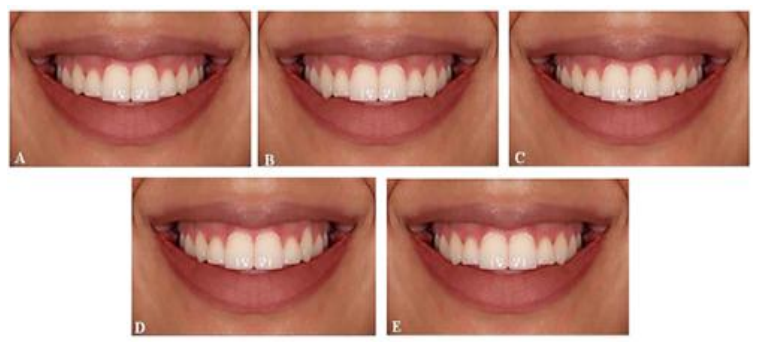

Fig. (1). Set one of the smile photographs with various lengths of canines. A. Canine tip of the same height as the central incisor edge (0), B. Canine tip longer by $1 \mathrm{~mm}$ in relation to the central incisor edge $(+1)$, C. Canine tip shorter by $1 \mathrm{~mm}$ in relation to the central incisor edge (-1), D. Canine tip shorter by $0.5 \mathrm{~mm}$ in relation to the central incisor edge (-0.5), E. Canine tip longer by $0.5 \mathrm{~mm}$ in relation to the central incisor edge $(+0.5)$.
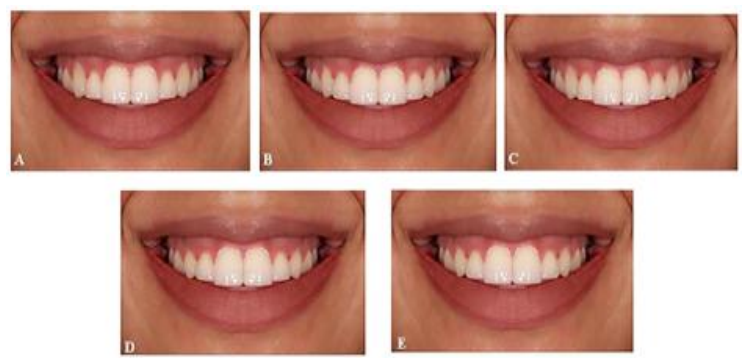

Fig. (2). Set two of smile photographs with various heights of gingiva of canines. A. Gingival height longer by $1 \mathrm{~mm}$ in relation to the central incisor (+1), B. Gingival height of the same height as the central incisor (0), C. Gingival height longer by $0.5 \mathrm{~mm}$ in relation to the central incisor $(+0.5)$, D. Gingival height shorter by $1 \mathrm{~mm}$ in relation to the central incisor $(-1)$, E.Gingival height shorter by $0.5 \mathrm{~mm}$ in relation to the central incisor $(-0.5)$.
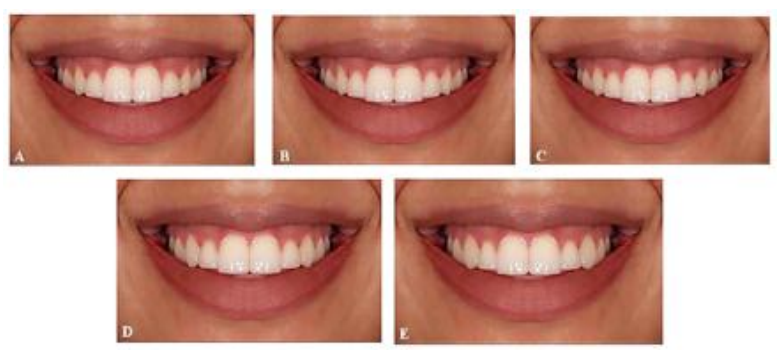

Fig. (3). Set three of the smile photographs with various Golden Proportions. A. Golden proportion of $52 \%$, B.Golden proportion of $57 \%$, C. Golden proportion of $62 \%$,D. Golden proportion of $67 \%$, E. Golden proportion of $72 \%$.

\subsection{Method of Data Collection}

Each photograph was printed in a 4 inch $\times 6$ inch paper with matt finish. All of them were provided unique identification numbers and shown to study participants. That way, each participant had to evaluate 5 photographs. Initially, the photographs were given in random order to each 
participant. They were asked to observe each photograph for 10 seconds and rate them out of 5 according to their perception. More rating would mean the participant finds the photograph aesthetically more attractive. The participants were instructed to organize the images with ascending order of ratings until they have achieved a final rank order within the given time and disregard the code at the back of each picture.

\subsection{Definitions Used}

\subsubsection{Golden Proportion}

Golden proportion means the percentage width of canine in relation to the lateral incisor. For example, a Golden Proportion of 52 means the visible width of canine in the photograph is $52 \%$, compared to the visible width of the lateral incisor.

\subsubsection{Data Entry and Analysis}

The data were entered in MS Excel 2010 and analysed with SPSS v23. The means and Standard Deviations (SD) of ratings were calculated and compared between different groups to identify if there was any significant difference between their perceptions. Kruskal Wallis Test and Mann Whitney U Test were applied as a test of significance (where ever applicable) and the level of significance was set at $<0.05$.

\section{RESULTS}

Table 1 describes the study groups. The mean age of students was 22.12 years. As expected, the mean age of general dentists was higher than the students (29.63 years). The mean age of laypersons was 28.9 years. The majority of the participants amongst students and laypersons were males (about 53\%). About $68.4 \%$ of general dentists had work experience of more than 3 years. The majority $(61.0 \%)$ of the dentistry students were from the $4^{\text {th }}$ profession.

Table 2 shows the rating of perception regarding canine length in comparison to central incisors. As it is evident, the statistically significant difference was seen only with the photograph where the canine tip was longer by $0.5 \mathrm{~mm}$ in relation to the central incisor edge. Laypersons gave the highest rating for this photograph (mean of 3.53 with $\mathrm{SD}$ of 1.33 ). The students of dentistry and General dentists found smiles with the canine tip of the same height as the central incisor edge (0) as most attractive. Compared to that, the laypersons found the canine tip longer by $0.5 \mathrm{~mm}$ in relation to the central incisor edge $(+0.5)$ as the most attractive.

Table 3 demonstrates that there was a significant difference in perceptions of three study populations regarding the gingival height [for $(-1),(-0.5), 0,(+0.5)$ and $(+1)]$. In case of the photograph with the gingival height of the same height as the central incisor (0), the highest mean score was given by the students of dentistry (3.61), while in case of the photograph with the gingival height longer by $1 \mathrm{~mm}(+1)$ in relation to the central incisor, the highest mean score was given by general dentists (3.26). Similarly, for photographs $(-1),(-0.5)$ and $(+0.5)$, the highest scores were given by laypersons (3.27), general dentists (3.26) and laypersons (4.20), respectively. The students of dentistry found the smiles with the gingival height of the same height as the central incisor (0) as the most attractive, while general dentists and laypersons found the gingival height longer by $0.5 \mathrm{~mm}$ in relation to the central incisor $(+0.5)$ as the most attractive.

Table 1. Characteristics of the study sample.

\begin{tabular}{|c|c|c|c|}
\hline Characteristics & $\begin{array}{c}\text { Dental } \\
\text { Students }\end{array}$ & $\begin{array}{c}\text { General Dental } \\
\text { Practitioners(N = } \\
\mathbf{3 8})\end{array}$ & $\begin{array}{c}\text { Lay } \\
\text { Persons }\end{array}$ \\
\hline & $\mathbf{( N = 4 1 )}$ & & $\mathbf{( N = 3 0 )}$ \\
\hline $\begin{array}{c}\text { Age (Mean } \pm \text { SD) in } \\
\text { completed years }\end{array}$ & $22.12 \pm 1.70$ & $29.63 \pm 3.44$ & $\begin{array}{c}28.90 \pm \\
3.0\end{array}$ \\
\hline Gender & & & \\
\hline Males & $22(53.7 \%)$ & $16(42.1 \%)$ & $16(53.3 \%)$ \\
\hline Females & $19(46.3 \%)$ & $22(57.9 \%)$ & $14(46.7 \%)$ \\
\hline Experience & & & \\
\hline 1-3 years & - & $12(31.6 \%)$ & - \\
\hline More than 3 years & - & $26(68.4 \%)$ & - \\
\hline Levels & & & \\
\hline 4th & $25(61.0 \%)$ & - & - \\
\hline 5th & $16(39.0 \%)$ & - & - \\
\hline
\end{tabular}

Table 2. Comparison of perception scores about the canine tip in different study groups.

\begin{tabular}{|c|c|c|c|c|}
\hline Characteristics & Dental Students & General Dental Practitioners & Lay Persons & p Value* \\
\hline & $($ Mean \pm SD) & $($ Mean \pm SD $)$ & $($ Mean \pm SD $)$ & \\
\hline Canine tip shorter by $1 \mathrm{~mm}$ in relation to the central incisor edge $(-1)$ & $3.12 \pm 1.63$ & $2.84 \pm 1.53$ & $2.40 \pm 1.38$ & 0.168 \\
\hline Canine tip shorter by $0.5 \mathrm{~mm}$ in relation to the central incisor edge $(-0.5)$ & $3.32 \pm 1.40$ & $3.13 \pm 1.61$ & $2.70 \pm 1.51$ & 0.274 \\
\hline Canine tip of the same height as the central incisor edge $(0)$ & $3.46 \pm 0.95$ & $3.18 \pm 1.08$ & $3.03 \pm 1.03$ & 0.095 \\
\hline Canine tip longer by $0.5 \mathrm{~mm}$ in relation to the central incisor edge $(+0.5)$ & $2.71 \pm 1.19$ & $3.16 \pm 1.05$ & $3.53 \pm 1.33$ & 0.014 \\
\hline Canine tip longer by $1 \mathrm{~mm}$ in relation to the central incisor edge $(+1)$ & $2.39 \pm 1.58$ & $2.61 \pm 1.64$ & $3.33 \pm 1.56$ & 0.061 \\
\hline
\end{tabular}

*Kruskal Wallis Test.

Table 3. Comparison of perception scores about the gingival height in different study groups.

\begin{tabular}{|c|c|c|c|c|}
\hline Characteristics & Dental Students & General Dental Practitioners & Lay Persons & p Value* \\
\hline & $($ Mean \pm SD) & $($ Mean \pm SD) & $($ Mean \pm SD) & \\
\hline Gingival height shorter by $1 \mathrm{~mm}$ in relation to the central incisor $(-1)$ & $2.54 \pm 1.46$ & $3.05 \pm 1.43$ & $3.27 \pm 0.98$ & 0.02 \\
\hline Gingival height shorter by $0.5 \mathrm{~mm}$ in relation to the central incisor $(-0.5)$ & $3.05 \pm 2.28$ & $3.26 \pm 1.00$ & $2.33 \pm 0.80$ & $<0.001$ \\
\hline
\end{tabular}


(Table 3) cont.....

\begin{tabular}{|c|c|c|c|c|}
\hline Characteristics & Dental Students & General Dental Practitioners & Lay Persons & p Value* \\
\hline & $($ Mean \pm SD) & $($ Mean \pm SD) & $($ Mean \pm SD) & \\
\hline Gingival height of the same height as the central incisor $(0)$ & $3.61 \pm 1.12$ & $2.11 \pm 1.35$ & $3.23 \pm 1.31$ & $<0.001$ \\
\hline Gingival height longer by $0.5 \mathrm{~mm}$ in relation to the central incisor $(+0.5)$ & $3.54 \pm 1.33$ & $3.32 \pm 1.71$ & $4.20 \pm 1.24$ & 0.033 \\
\hline Gingival height longer by $1 \mathrm{~mm}$ in relation to the central incisor(+1) & $2.27 \pm 1.42$ & $3.26 \pm 1.18$ & $1.97 \pm 1.52$ & 0.001 \\
\hline
\end{tabular}

*Kruskal Wallis H Test.

As evident from Table 4, the Golden Proportion of 52\% was given mean scores of less than 3 by all three groups. No significant difference in the perception of smile aesthetics was observed except in the case of the Golden Proportion of $72 \%$. In the case of the Golden Proportion of $72 \%$, the highest mean score was given by general dentists. The dental students found Golden Proportion of $62 \%$ as the most attractive, while general dentists and laypersons found Golden Proportions of $72 \%$ and $57 \%$ as the most attractive, respectively.

Table 5 shows a comparison of perceptions about smile aesthetics between different groups. The perceptions of students of dentistry and general dentists were almost similar (with no statistical difference) in case of photographs with varying lengths of maxillary canines. However, a significant difference between these two groups was found for the photograph with "gingival height similar to that of the central incisors" and "higher than central incisors by $1 \mathrm{~mm}$ ". Similarly, a significant difference was also found for the photograph with a Golden Proportion of $72 \%$. When perceptions of general dentists were compared with laypersons, significant differences in the perceptions were observed, especially for photographs with varying gingival heights. The significant difference between these two groups was also found for the photographs with the canine length of $(+1)$ and the Golden Proportion of $72 \%$. Upon comparing the perceptions of dental students with laypersons, significant differences were observed for canine lengths of $(0),(+0.5)$ and $(+1)$, and the gingival height of $(-1),(-0.05)$ and $(+0.05)$.

Table 4. Comparison of perception scores about the Golden Proportion in different study groups.

\begin{tabular}{|c|c|c|c|c|}
\hline Golden Proportion (\%) & Dental Students & General Dental Practitioners & Lay Persons & $\mathbf{p}$ Value* \\
\hline 52 & $2.78 \pm 1.26$ & $2.50 \pm 1.27$ & $2.67 \pm 1.84$ & 0.58 \\
\hline 57 & $3.41 \pm 1.34$ & $2.87 \pm 1.40$ & $3.53 \pm 1.66$ & 0.103 \\
\hline 62 & $3.63 \pm 1.22$ & $3.16 \pm 1.75$ & $2.87 \pm 1.61$ & 0.174 \\
\hline 67 & $2.85 \pm 1.39$ & $2.84 \pm 1.37$ & $3.00 \pm 1.36$ & 0.92 \\
\hline 72 & $2.32 \pm 1.52$ & $3.63 \pm 1.02$ & $2.90 \pm 1.09$ & $<0.001$ \\
\hline
\end{tabular}

*Kruskal Wallis H Test.

Table 5. Comparison of the perception of the smile as "attractive" between different groups.

\begin{tabular}{|c|c|c|c|}
\hline Characteristics & $\begin{array}{c}\text { Comparison of Dental Students and } \\
\text { General Dentists (p value*) }\end{array}$ & $\begin{array}{c}\text { Comparison of General Dentists and } \\
\text { Lay Persons (p value*) }\end{array}$ & $\begin{array}{c}\text { Comparison of Dental Students and } \\
\text { Lay Persons (p value*) }\end{array}$ \\
\hline Canine length & & & 0.07 \\
\hline-1 & 0.531 & 0.107 & 0.099 \\
\hline-0.5 & 0.704 & 0.102 & 0.041 \\
\hline 0 & 0.206 & 0.473 & 0.011 \\
\hline 0.5 & 0.063 & $<0.001$ & 0.025 \\
\hline 1 & 0.693 & 0.086 & 0.01 \\
\hline Gingival Height & & & 0.013 \\
\hline-1 & 0.091 & 0.199 & 0.385 \\
\hline-0.5 & 0.449 & $<0.001$ & 0.021 \\
\hline 0 & $<0.001$ & 0.001 & 0.197 \\
\hline 0.5 & 0.828 & 0.036 & 0.86 \\
\hline 1 & 0.002 & 0.001 & 0.55 \\
\hline Golden Proportion (\%) & & & 0.051 \\
\hline 52 & 0.341 & 0.48 & 0.652 \\
\hline 57 & 0.098 & 0.068 & 0.028 \\
\hline 62 & 0.37 & 0.511 & \\
\hline 67 & 0.933 & 0.857 & \\
\hline 72 & $<0.001$ & 0.013 & \\
\hline
\end{tabular}

\footnotetext{
*Mann-Whitney U Test.
} 
Table 6 shows how much proportions of subjects found the photographs with different dimensions of canines as "attractive", in each study group. The overall mean scores (with SD) across all three groups were calculated. It was found that the highest score was found with a canine length of $(0)$ with a mean score of $3.25 \pm 1.03$. Similarly, in the case of gingival heights, the highest score was with a height of $(+0.5)$ (mean score of $3.64 \pm 1.48$ ). The Golden Proportions of $57 \%$ and $62 \%$ fetched almost similar scores of $3.26 \pm 1.47$ and 3.26 \pm 1.55 , respectively. The scores above 2.5 were considered as an indication of finding the smile as "attractive" and scores lower than 2.5 were considered as "not attractive". Based on these criteria, interesting results were found. In the case of the canine length, maximum students of dentistry(87.8\%) found the length of $(0)$ as attractive. Similarly, amongst general dentists, the majority (76.3\%) found the length of (0) as attractive. These findings differed in the group of laypersons, majority of them (73.3\%) found canine lengths of $(0)$ and $(+1)$ as attractive. In the case of the gingival height, maximum students $(82.9 \%)$ found the height of $(0)$ as attractive. Compared to that, the majority of dentists $(84.2 \%)$ found the height of $(-0.5)$ as attractive. In the case of laypersons, the majority of them $(93.3 \%)$ found $(+0.5)$ as attractive. About $82.9 \%$ of the students found the Golden Proportion of $62 \%$ as attractive, which constituted the majority. Amongst general dentists, the majority (86.8\%) found the Golden Proportion of $67 \%$ as attractive. While, the majority of laypersons $(73.3 \%)$ preferred Golden Proportions of $52 \%$ and $57 \%$ as attractive.

\section{DISCUSSION}

The role of dentists has expanded from mere correction of mal-occluding or mal-positioned teeth to "architects" of a smile. Maxillary canines have a major impact on the appearance of the smile. Little changes in their dimensions can give a patient much needed self-confidence. The perception of an ideal smile varies from person to person. However, there cannot be uniform dimensions of teeth, which can be perceived as the ideal smile, as the perception has a subjective component and it varies from person to person. In fact, it is affected by a number of factors $[1,5]$. It is not necessary that the perception of an orthodontic professional should coincide with that of laypersons $[4,6]$.The current study has emphasised on the role of maxillary canines in smile aesthetics and perception of socio-demographically different groups towards varying dimensions of canines.

The current study demonstrated that the perceptions of different groups involved in the study, about smile aesthetics, varied for various dimensions of canine. A study conducted by Correa et al. also demonstrated a vast difference between perceptions of orthodontists and laypersons. ${ }^{4}$ This difference in the perception is not limited to the lengths of canine, but also observed in the case of incisors' dimensions [7 - 9]. Overall, it was found that all three groups found the canine tips longer than central incisors more attractive. The current study found that the students of dentistry and general dentists found smiles with a canine tip of the same height as the central incisor edge (0) as most attractive. A similar result was also found by Li et al., who compared perceptions of orthodontists with laypersons, but they compared the canine height with the central incisor [10]. They also found that the laypersons gave a maximum score for the canine tip (0). This result differed from the findings of the current study, which demonstrated that the laypersons gave a maximum score to photographs with the canine tip longer by $0.5 \mathrm{~mm}$ in relation to the central incisor edge $(+0.5)$.

In the current study, dental students and general dentists have given maximum scores to $62 \%$ and $72 \%$ Golden Proportions, respectively. It is also demonstrated that general dentists were able to perceive the $72 \%$ Golden Proportion as most attractive, compared to laypersons. This again goes to show that the perception of laypersons can be drastically different from an orthodontist. One of the major factors for this is the inability of laypersons to perceive a difference in various Golden Proportions [8, 11, 12,].

This study is unique as not many studies have evaluated the effect of dimensions of canines on smile aesthetics. The current study was conducted with a convenient sample size due to the limited number of resources, which is a major limitation of the study. The study used photographs of a female to find the perceptions of participants. It can be assumed that using photographs of males may produce different results. Being an upcoming aspect of dentistry, smile aesthetics require further research with larger sample sizes to identify subjective perceptions.

Table 6. Perceptions of dimensions of canines on the smile as "attractive" by different groups.

\begin{tabular}{|c|c|c|c|c|}
\hline Characteristics & Mean Score \pm Standard Deviation & Students of Dentistry & General Dental Practitioners & Lay Persons \\
\hline & & $\mathbf{N}$ (\%) & $\mathbf{N ~ ( \% ) ~}$ & $\mathbf{N}(\%)$ \\
\hline Canine length & & & & \\
\hline-1 & $2.83 \pm 1.55$ & $26(63.4)$ & $19(50.0)$ & $12(40.0)$ \\
\hline-0.5 & $3.08 \pm 1.52$ & $28(68.3)$ & $21(55.7)$ & $13(43.3)$ \\
\hline 0 & $3.25 \pm 1.03$ & $36(87.8)$ & $29(76.3)$ & $22(73.3)$ \\
\hline 0.5 & $3.09 \pm 1.22$ & $20(48.8)$ & $26(68.4)$ & $21(70.0)$ \\
\hline 1 & $2.72 \pm 1.63$ & $13(31.7)$ & $22(57.9)$ & $22(73.3)$ \\
\hline Gingival Height & & & & \\
\hline-1 & $2.92 \pm 1.36$ & $17(41.5)$ & $18(47.4)$ & $25(83.3)$ \\
\hline-0.5 & $2.93 \pm 1.13$ & $20(48.8)$ & $32(84.2)$ & $7(23.3)$ \\
\hline 0 & $2.98 \pm 1.41$ & $34(82.9)$ & $14(36.8)$ & $21(70.0)$ \\
\hline 0.5 & $3.64 \pm 1.48$ & $31(75.6)$ & $21(55.3)$ & $28(93.3)$ \\
\hline
\end{tabular}


(Table 6) cont.....

\begin{tabular}{|c|c|c|c|c|}
\hline Characteristics & Mean Score \pm Standard Deviation & Students of Dentistry & General Dental Practitioners & Lay Persons \\
\hline & & $\mathbf{N}(\%)$ & $\mathbf{N}(\%)$ & $\mathbf{N}(\%)$ \\
\hline 1 & $2.53 \pm 1.46$ & $15(36.6)$ & $29(76.3)$ & $9(30.0)$ \\
\hline \multicolumn{5}{|c|}{ Golden Proportion (\%) } \\
\hline 52 & $2.65 \pm 1.24$ & $23(56.1)$ & $20(52.4)$ & $22(73.3)$ \\
\hline 57 & $3.26 \pm 1.47$ & $30(73.1)$ & $26(68.4)$ & $22(73.3)$ \\
\hline 62 & $3.26 \pm 1.55$ & $34(82.9)$ & $21(5.3)$ & $16(53.4)$ \\
\hline 67 & $2.89 \pm 1.36$ & $22(53.7)$ & $14(36.8)$ & $16(53.4)$ \\
\hline 72 & $2.94 \pm 1.36$ & $14(34.2)$ & $33(86.8)$ & $14(46.6)$ \\
\hline
\end{tabular}

\section{CONCLUSION}

The study concluded that the study of dentistry affects the perception to identify and perceive different dimensions of canines, in terms of attractiveness, when compared to laypersons (who do not have studied dentistry). The most of the dental students found the canine tip (0), the gingival height of ( 0$)$ and the Golden Proportion $62 \%$ as attractive. The majority of general dentists found the canine tip (0), the gingival height of (-0.5) and the Golden Proportion $72 \%$ as attractive. In comparison, laypersons found the canine tip (0), the gingival height of $(+0.5)$ and Golden Proportions of 52\% and $57 \%$ as attractive.

\section{ETHICS APPROVAL AND CONSENT TO PARTI- CIPATE}

This article does not contain any studies with human participants or animals performed by any of the authors.

\section{HUMAN AND ANIMAL RIGHTS}

Not applicable.

\section{CONSENT FOR PUBLICATION}

Written informed consent was obtained from all participants.

\section{AVAILABILITY OF DATA AND MATERIALS}

The data that support the findings of this study are available from the corresponding author, [A.A.T], upon reasonable request.

\section{FUNDING}

This research did not receive any specific grant from funding agencies in the public, commercial, or not-for-profit sectors.

\section{CONFLICT OF INTEREST}

The authors declare no conflict of interest, financial or otherwise.

\section{ACKNOWLEDGEMENTS}

Declared none.

\section{REFERENCES}

[1] Afroz S, Rathi S, Rajput G, Rahman SA. Dental esthetics and its impact on psycho-social well-being and dental self confidence: A campus based survey of north Indian university students. J Indian Prosthodont Soc 2013; 13(4): 455-60.

[http://dx.doi.org/10.1007/s13191-012-0247-1] [PMID: 24431775]

[2] Prasad V, Tandon P, Sharma VP, Singh GK, Maurya RP, Chugh V. Photographical evaluation of smile esthetics after extraction orthodontic treatment. J Orthop Res 2015; 3: 49-56.

[3] Heravi F, Ahrari F, Rashed R, Heravi P, Ghaffari N, Habibirad A. Evaluation of factors affecting dental esthetics in patients seeking orthodontic treatment. Int J OrthodRehabil 2016; 7: 79-84.

[4] Correa BD, Vieira Bittencourt MA, Machado AW. Influence of maxillary canine gingival margin asymmetries on the perception of smile esthetics among orthodontists and laypersons. Am J Orthod Dentofacial Orthop 2014; 145(1): 55-63.

[http://dx.doi.org/10.1016/j.ajodo.2013.09.010] [PMID: 24373655]

[5] Katiyar S, Gandhi S, Sodawala J, Anita G, Hamdani S, Jain S. Influence of symmetric and asymmetric alterations of maxillary canine gingival margin on the perception of smile esthetics among orthodontists, dentists, and laypersons. Indian J Dent Res 2016; 27(6): 586-91.

[http://dx.doi.org/10.4103/0970-9290.199593] [PMID: 28169254]

[6] Miller CJ. The smile line as a guide to anterior esthetics. Dent Clin North Am 1989; 33(2): 157-64.

[PMID: 2656315]

[7] Al Taki A, Guidoum A. Facial profile preferences, self-awareness and perception among groups of people in the United Arab Emirates. J Orthod Sci 2014; 3(2): 55-61

[http://dx.doi.org/10.4103/2278-0203.132921] [PMID: 24987664]

[8] Cotrim ER, Vasconcelos Júnior ÁV, Haddad AC, Reis SA. Perception of adults' smile esthetics among orthodontists, clinicians and laypeople. Dental Press J Orthod 2015; 20(1): 40-4.

[http://dx.doi.org/10.1590/2176-9451.20.1.040-044.oar] [PMID: 25741823]

[9] Alyami AH, Al Sanea J, Togoo RA, Ain TS. Aesthetic Perception about Gingival Display on Maxillary Incisor Inclination among Saudi Dentists, Orthodontist and Lay Persons. J Clin Diagn Res 2018; 12 : 56-60.

[http://dx.doi.org/10.7860/JCDR/2018/33965.11835]

[10] Li R, Mei L, Wang P, et al. Canine edge width and height affect dental esthetics in maxillary canine substitution treatment. Prog Orthod 2019; 20(1): 16 .

[http://dx.doi.org/10.1186/s40510-019-0268-y] [PMID: 30957211]

[11] Dhiraj R, Rajaganesh G, Kunal M, Ajit K. Do facial photographs help in the evaluation of self-perception of patients towards dentofacial attractiveness? Dentistry 2015; 5: 304.

[12] Bonetti GA, Alberti A, Sartini C, Parenti SI. Patients's self-perception of dentofacial attractiveness before and after exposure to facial photographs. Angle Orthod 2011; 81(3): 517-24. [http://dx.doi.org/10.2319/101510-606.1] [PMID: 21299386] 